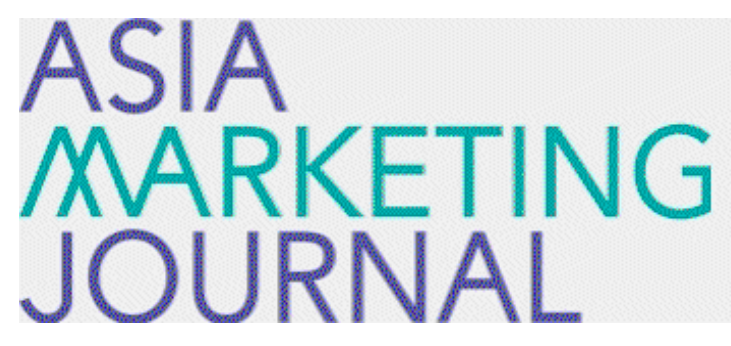

ASIA MARKETING JOURNAL

Volume 11 | Issue 3

Article 2

10-30-2009

\title{
A Study of the Extended Service Norm Constructs Influencing Behavioral Intention and a Moderating Variable in Service Purchasing Situation
}

Sang Hyun Lee

Sang Jun Lee

Follow this and additional works at: https://amj.kma.re.kr/journal

Part of the Marketing Commons

\section{Recommended Citation}

Lee, Sang Hyun and Lee, Sang Jun (2009) "A Study of the Extended Service Norm Constructs Influencing Behavioral Intention and a Moderating Variable in Service Purchasing Situation," Asia Marketing Journal: Vol. 11 : Iss. 3 , Article 2.

Available at: https://doi.org/10.53728/2765-6500.1392

This Article is brought to you for free and open access by Asia Marketing Journal. It has been accepted for inclusion in Asia Marketing Journal by an authorized editor of Asia Marketing Journal. 


\title{
A Study of the Extended Service Norm Constructs Influencing Behavioral Intention and a Moderating Variable in Service Purchasing Situation
}

\author{
Lee, Sang Hyun* \\ Lee, Sang Jun**
}

\begin{abstract}
The purpose of this study is to develop a service norm construct influencing behavioral intention in a service purchasing situation and investigate how the construct is related with other constructs in the theory of planned action model. Furthermore, a moderating variable, self-monitoring concept, in the model is considered.

As a result, the influence of attitude, subjective norm, and perceived control on behavioral intention were all significant. Other consumers' norm was a significant factor affecting behavioral intention. Service provider norm, however, was not significant. In addition, self-monitoring played a moderating role in the model.

The implication of this study is that service company or manager should consider service customer compatibility because focal customers are conscious that they face other customer's response.

Key words: Service providers' norm, Other customers' norm, Self-monitoring, Behavioral intention
\end{abstract}

* Associate Professor, School of Business, Dongguk University

** Ph. D. Candidate, School of Business, Dongguk University

24 한국마케팅저널 제11권 제3호 2009년 10월 


\section{Introduction}

According to Fishbein's attitude theory, a positive attitude toward a product brand will increase the possibility of intention to buy. To better explain the relationship between attitude and behavior, Fishbein and Ajzen (1975, 1980) modified Fishbein's attitude model. Theory of Reasoned Action (TRA) proposed that subjective norms as well as attitudes should be considered to predict intentions. Ajzen (1985, 1988, 1991), however, introduced theory of Planned Behavior (TPB) considering perceived control factor.

Those behavioral intention models have been empirically tested in many studies (Farley, Lehman, \& Ryan 1981; Shimp \& Kavas 1984; Sheppard, Hartwick, \& Warshaw 1988; Cooke \& Sheeran 2004; Pavlou \& Fygenson 2006). However, those models are not good enough to explain behavioral intention and yet there may be other factors to consider (Sheeran 2002). In fact, the past studies had been limited to a product purchasing behavior and personal interesting behavior. In service purchasing behavior situation, however, customers may consider what service providers and/or other people who are participated in the service system think.

Lee, Yoo, and Jang (2007) proposed that perceived service provider and/or other customers thought should be considered as another important factor to explain the behavioral inten- tion in the service context. Most customers may concern what other customers or service providers are involved in the situation while they are consuming or purchasing a service.

The purpose of this study is to introduce two service related norm constructs influencing behavioral intention in a service purchasing situation. In addition, it is to investigate how the constructs are related with the behavioral intention along with other constructs in the theory of planned action model. Furthermore, a moderating variable, self-monitoring concept, in the model is considered.

\section{Theoretical framework and Hypotheses}

This study introduces the influence of $\mathrm{ex}^{-}$ tended norm constructs on behavioral intention to buy or consume various services and moderating role of self-monitoring between critical factors and service intention. A research model is shown in 〈Figure 1). The research model proposes a certain relationship between behavioral intention and two different constructs (service providers' norm and other customers' norm) as the extended norm along with three constructs (attitude, subjective norm, perceived control) which has been shown in the past TPB model.

Service provider's norm, an extended norm 


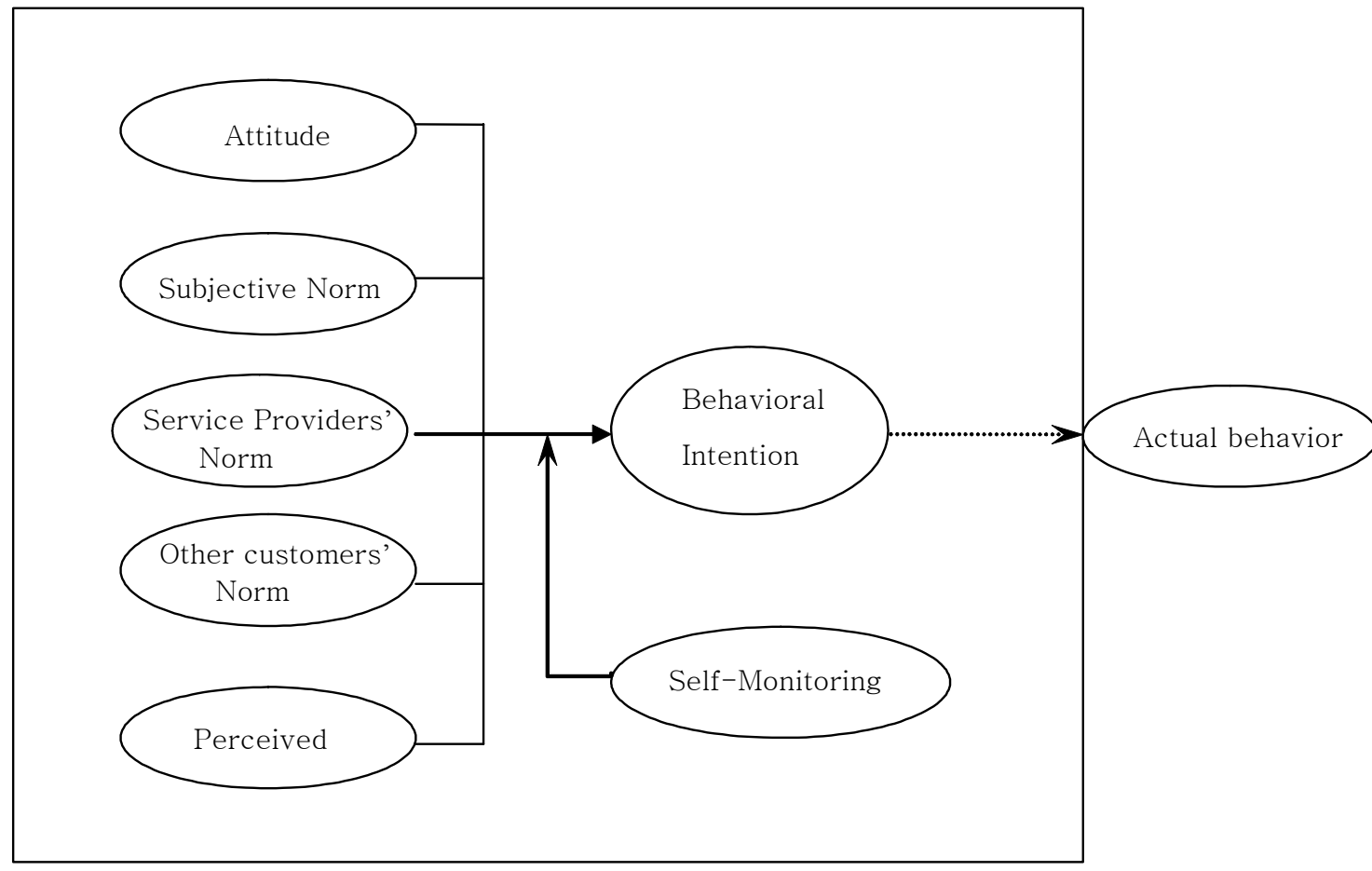

construct, is different from subjective norm. Subjective norm is a perceived social pressure that consumers may feel to purchase a certain product. Service provider's norm, however, is another pressure directly from the service providers while consumers are trying to purchase and/or use a service in the service system so that this pressure may be stronger than the general pressure from subjective norm. In addition, other customers' norm is intended to reflect additional perceived pressure that the customers may feel to use and/or purchase a certain service. These service related norms should be considered to get better understanding why customers are intend to perform a certain behavior in a service encounter.

In addition, a moderating variable, self-monitoring is introduced in the model to better understand the linkage among attitude, subjective norm, and the extended norms such as other customer's norm and service providers' norm. Self-monitoring is a sensitivity or an alertness to social cues so that individuals modify their behavior. Based on the theoretical background of TPB and extended service related norm constructs, the following hypotheses are tested:

Hypothesis 1: Service purchasing intention is significantly determined by the attitude toward the service. 
Hypothesis 2: Service purchasing intention is significantly determined by the subjective norm.

Hypothesis 3: Service purchasing intention is significantly determined by the perceived behavioral control.

Hypothesis 4: Service purchasing intention is significantly determined by the service provider's norm.

Hypothesis 5: Service purchasing intention is significantly determined by the other customer's norm.

Hypothesis 6: The influence of service norms on service purchasing intention is likely to increase as the level of self-monitoring increases.

\section{Research Method}

Types of services situation should be considered before conducting a statistical method in this study. The results and interpretation of results might be different depending on types of services because the range of services is very wide. Therefore, pre-test was conducted to select the appropriate types of services situation to test linkage among the extended norm constructs, attitudes, and behavioral intention.

Students and staffs in a college were participated in the pre-test to respond various services purchasing situation. Both using a club service and using a body scrubber service in a public bath were finally chosen among many other services situation. Using a club service situation might not be sensitive issue for college students, but it may be sensitive for over 40s people. Meanwhile, using a body scrubber service situation might be sensitive issue for college students, but not for over 40s people. Students are aware of the body scrubber and/ or other people who are in the service system when they are trying to use the scrubbing service.

Based on the pre-test, a questionnaire for each service situation scenario was developed. Participants in the main test were 500 adults who live in Seoul. These adults were asked to complete a self-administered questionnaire from a personal interviewer.

\section{Results}

A structural equation modeling (SEM) using the AMOS program was used to test the linkage among the extended service norm constructs along with the variables in TPB and behavioral intention. The measurement model was used to confirm the validation of the constructs. Then the structural model was estimated to evaluate the relationships among the latent variables.

Twenty items were employed as indicators of the six latent constructs: Attitude, subjective norm, service providers' norm, other customers' norm, perceived behavioral control, and behavioral 
intention. An inspection of reliabilities and variance extracted for each construct revealed that the measurement model was highly reliable and reasonably valid. The overall fit indices indicate a Chi-square of 468.239 with 155 degrees of freedom $(p<0.001)$. The absolute fit indices are RMSEA $=0.065$, GFI $=0.91$, AGFI $=0.879$, NNFI $=0.949, \mathrm{CFI}=0.959$. The overall, fit statistics showed a good fit except for AGFI. However, an AGFI value of .88 can be considered to be within a close fit range.

The major results are shown in 〈Table 5〉. This proposed model shows good fit to the data $\left(\chi^{2}=468.236(\mathrm{p}=0.000), \mathrm{df}=155, \mathrm{GFI}=\right.$ 0.910, $\mathrm{AGFI}=0.879$, NFI $=0.940, \mathrm{NNFI}=0.949$, $\mathrm{CFI}=0.959$, RMSEA $=0.065)$. As a result shown in 〈Table 5〉, Hypothesis 1, 2, and 5 concerned the influence of factors in TPB model on behavioral intention was strongly supported. Hypothesis four concerning the influence of other customers' norm on behavioral intention was supported as well. Hypothesis three concerning the effect of service providers' norm on behavioral intention, however, was not supported.

The result of hypothesis 6 concerning moderating effect of self-monitoring is as shown in $\langle$ Table 6〉 and $\langle$ Table 7$\rangle$. To analyze hypothesis 6, multi-group strategy in SEM was conducted. Self-monitoring was divided into two groups using the median value; the low group ( $n=209)$ and the high group $(n=275)$.

The construct, self-monitoring was simply considered as being conscious of the surrounding people in a service purchasing situation. It was predicted that two services related norms would have a greater effect on behavioral intention in the high self-monitoring group. Service providers' norm and other customers' norm, however, had influence on behavioral intention in the low self-monitoring group, but not in the high self-monitoring group.

Results of the comparison through $\chi^{2}$ difference revealed that the moderating effect of self-monitoring between service related norms and behavioral intention was statistically significant at the level of 0.01 and 0.05 respectively $\left(\Delta \chi^{2}=8.941, \mathrm{p}<0.01, \Delta \chi^{2}=4.448, \mathrm{p}<0.05\right)$.

$\langle$ Table 5〉 Influence of main constructs on behavioral intention

\begin{tabular}{c|l|c|c|c|}
\hline & \multicolumn{1}{|c|}{ Path } & Estimate & S.E. & t-value \\
\hline \hline H1 & Attitude $\rightarrow$ Behavioral Intention & .479 & .064 & $7.516^{* * *}$ \\
\hline H2 & Subjective norm $\rightarrow$ Intention & .236 & .057 & $4.121^{* * *}$ \\
\hline H3 & Service providers' norm $\rightarrow$ Intention & -.056 & .063 & -.888 \\
\hline H4 & Other customers' norm $\rightarrow$ Intention & .117 & .068 & $1.732^{*}$ \\
\hline H5 & Perceived behavioral Control $\rightarrow$ Intention & .481 & .057 & $8.473^{* * *}$ \\
\hline
\end{tabular}

* $\mathrm{p}<0.1,{ }^{* *} \mathrm{p}<0.05, * * * \mathrm{p}<0.01$ 
〈Table 6〉 Moderating effect of Self-Monitoring

\begin{tabular}{l|c|c|c|c}
\hline \multirow{2}{*}{ Path } & \multicolumn{2}{c|}{$\begin{array}{c}\text { Low self-monitoring group } \\
(\mathrm{N}=209)\end{array}$} & \multicolumn{2}{c}{$\begin{array}{c}\text { High self-monitoring group } \\
(\mathrm{N}=275)\end{array}$} \\
\cline { 2 - 5 } & Estimate & $\mathrm{t}$-value & Estimate & t-value \\
\hline \hline Attitude $\rightarrow$ Behavioral Intention & .525 & $4.698^{* * *}$ & .474 & $5.481^{* * *}$ \\
\hline Subjective Norm $\rightarrow$ Intention & .284 & $3.302^{* * *}$ & .208 & $2.735^{* *}$ \\
\hline Service Providers' Norm $\rightarrow$ Intention & -.318 & $-2.975^{* *}$ & .085 & 1.026 \\
\hline Other Customers' Norm $\rightarrow$ Intention & .352 & $2.652^{* *}$ & .030 & .391 \\
\hline Perceived behavioral Control $\rightarrow$ Intention & .413 & $3.440^{* * *}$ & .504 & $7.641^{* * *}$ \\
\hline
\end{tabular}

${ }^{*} \mathrm{p}<0.1, * * \mathrm{p}<0.05, * * * \mathrm{p}<0.01$

$\langle$ Table 7〉 Chi-squares difference test

\begin{tabular}{l|c|c|c|c}
\hline \multicolumn{1}{c|}{ Path } & $\chi^{2}$ & $\mathrm{df}$ & $\Delta \chi^{2}$ & sig \\
\hline \hline Free & 701.988 & 310 & - & - \\
\hline Attitude $\rightarrow$ Behavioral Intention & 702.117 & 311 & .128 & n.s \\
\hline Subjective Norm $\rightarrow$ Behavioral Intention & 702.416 & 311 & .428 & n.s \\
\hline Service providers' Norm $\rightarrow$ Behavioral Intention & 710.929 & 311 & 8.941 & $\mathrm{p}<0.01$ \\
\hline Other customers' Norm $\rightarrow$ Behavioral Intention & 706.437 & 311 & 4.448 & $\mathrm{p}<0.05$ \\
\hline Perceived Control $\rightarrow$ Behavioral Intention & 702.411 & 311 & .423 & n.s \\
\hline
\end{tabular}

\section{Conclusion}

The contribution of this study is to apply the theory of the planned action model to the service purchasing situation. Furthermore, the study proposed that the extended service norms should be considered to get better explanation of the behavioral intention in the service encounter. 